\title{
Changes of fatty acid aerosol hygroscopicity induced by ozonolysis under humid conditions
}

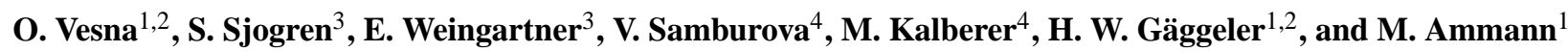 \\ ${ }^{1}$ Laboratory of Radio- and Environmental Chemistry, Paul Scherrer Inst., Villigen, Switzerland \\ ${ }^{2}$ Department of Chemistry and Biochemistry, University of Bern, Bern, Switzerland \\ ${ }^{3}$ Laboratory of Atmospheric Chemistry, Paul Scherrer Institut, Villigen, Switzerland \\ ${ }^{4}$ Institute of Organic Chemistry, ETH Zürich, Zürich, Switzerland
}

Received: 1 October 2007 - Published in Atmos. Chem. Phys. Discuss.: 1 November 2007

Revised: 24 June 2008 - Accepted: 9 July 2008 - Published: 18 August 2008

Abstract. Unsaturated fatty acids are important constituents of the organic fraction of atmospheric aerosols originating from biogenic or combustion sources. Oxidative processing of these may change their interaction with water and thus affect their effect on climate. The ozonolysis of oleic and arachidonic acid aerosol particles was studied under humid conditions in a flow reactor at ozone exposures close to atmospheric levels, at concentrations between 0.5 and $2 \mathrm{ppm}$. While oleic acid is a widely used proxy for such studies, arachidonic acid represents polyunsaturated fatty acids, which may decompose into hygroscopic products. The hygroscopic (diameter) growth factor at $93 \%$ relative humidity (RH) of the oxidized arachidonic particles increased up to 1.09 with increasing RH during the ozonolysis. In contrast, the growth factor of oleic acid was very low (1.03 at 93\% $\mathrm{RH})$ and was almost invariant to the ozonolysis conditions, so that oleic acid is not a good model to observe oxidation induced changes of hygroscopicity under atmospheric conditions. We show for arachidonic acid particles that the hygroscopic changes induced by humidity during ozonolysis are accompanied by about a doubling of the ratio of carboxylic acid protons to aliphatic protons. We suggest that, under humid conditions, the reaction of water with the Criegee intermediates might open a pathway for the formation of smaller acids that lead to more significant changes in hygroscopicity. Thus the effect of water to provide a competing pathway during ozonolysis observed in this study should be motivation to include water, which is ubiquitously present in and around atmospheric particles, in future studies related to aerosol particle aging.

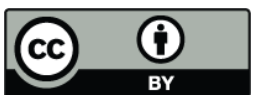

Correspondence to: M. Ammann (markus.ammann@psi.ch)

\section{Introduction}

Atmospheric aerosols consist of both inorganic and organic compounds. Field measurements indicate that the organic fraction of atmospheric aerosols is in the range from 20 to $90 \%$, depending on the location and sources (Kanakidou et al., 2005; Jacobson et al., 2000; Novakov and Penner, 1993; Seinfeld and Pandis, 1998). Fatty acids, i.e., n-alkanoic and n-alkenoic acids, can make up a significant contribution to the organic fraction, they have been found in emissions from biomass burning (Oros and Simoneit, 2001), coal burning (Oros and Simoneit, 2000), fossil fuel combustion (Rogge et al., 1993), cooking (Rogge et al., 1991; Schauer et al., 1999), plants of the terrestrial biosphere (Cheng et al., 2004; Simoneit et al., 1988; Simoneit and Mazurek, 1982), and also in marine aerosols, where they are associated with sea salt aerosol and stem from degradation of marine biota (Mochida et al., 2002; Tervahattu et al., 2002). In all these sources, a significant fraction of fatty acids are unsaturated alkenoic acids (Kawamura and Gagosian, 1987; Wang et al., 2006). Some of these are polyunsaturated fatty acids, i.e., have more than one double bond, and their concentration may exceed the concentrations of monounsaturated fatty acids (Polzer and Bachmann, 1991). Given their amphiphilic nature, fatty acids can be considered as potentially important aerosol surfactants (Ellison et al., 1999; Tervahattu et al., 2002).

Processing of organic particulate matter by oxidants in the atmosphere is believed to significantly contribute to aerosol hygroscopicity and CCN activity that in turn influence the direct and indirect aerosol effects on the Earth's radiation balance (Kanakidou et al., 2005). A number of studies suggested the importance of the transformation of fatty acid surfactants by oxidative processing (Ellison 1999; FinlaysonPitts, 1999). Thereby, the organic layer can be transformed from an inert, hydrophobic film to a reactive, optically active

Published by Copernicus Publications on behalf of the European Geosciences Union. 


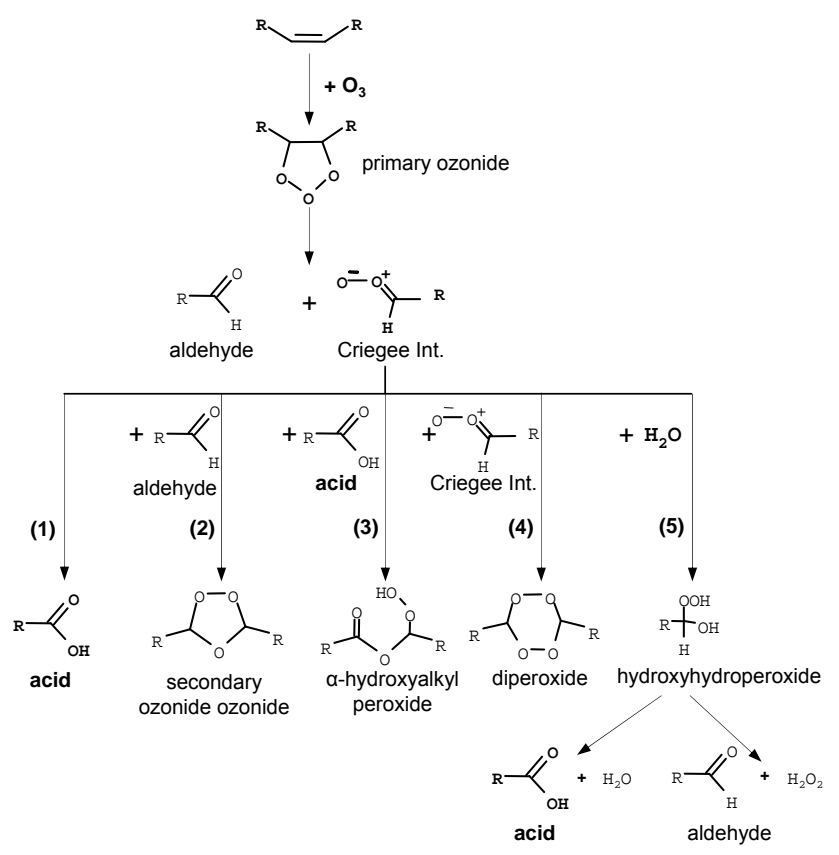

Fig. 1. Reaction mechanism for the ozonolysis of an unsaturated double bond. Formation pathways of acids, aldehydes, secondary ozonides, $\alpha$-hydroxyalkyl peroxides and diperoxides in presence and absence of water.

hydrophilic layer. Unsaturated fatty acids are particularly susceptible to oxidation due to the reactivity of the double bond with ozone.

A number of laboratory studies has used ozonolysis of oleic acid as a model system of fatty acids to investigate the chemistry of organic particle aging and its relation to aerosol hygroscopicity (Zahardis and Petrucci, 2007). However, significant absorption of water by oxidized oleic acid drops and films was only evident at very high ozone concentration (up to $500 \mathrm{ppm}$ ) and relative humidity above $90 \%$ (Asad et al., 2004; Hung et al., 2005; Hung and Ariya, 2007), and it has been argued that these conditions may not have been relevant for the atmosphere (Zahardis and Petrucci, 2007). Only very recently, Lee and Chan (2007a) have reported a very low hygroscopic growth factor after exposure of oleic acid to low concentrations of ozone over extended periods of time.

In this work, we exposed oleic acid (OA) and arachidonic acid (AR) aerosol particles to ozone and humidity under conditions as close as possible to ambient to establish a link between condensed phase alkene oxidation and hygroscopic growth. The goal was to determine the hygroscopic growth factor (GF) as function of ozone concentration and humidity and to relate the observed hygroscopic changes with the functional group composition of product particles. OA is a C18 monounsaturated fatty acid with a double bond at the C9 position, and AR is a polyunsaturated $\mathrm{C} 20$ fatty acid with four double bonds at the $\mathrm{C} 5, \mathrm{C} 8, \mathrm{C} 11$ and $\mathrm{C} 14$ positions. Ozone attacks at the carbon-carbon double bonds, which leads to primary ozonides that then decompose into a range of products. A simplified scheme is given in Fig. 1. For OA the products are non-hygroscopic $\mathrm{C} 9$ acids, aldehydes and oligomers thereof (Zahardis and Petrucci, 2007). The AR-ozone reaction may lead to shorter chain species, including hygroscopic $\mathrm{C} 3$ and $\mathrm{C} 5$ dicarboxylic acids. The effect of water on condensed phase alkene oxidation has not been entirely clarified so far, even though the reaction of the Criegee intermediates with water had been suggested to be significant in the gas phase (Hasson et al., 2001a). Very recently, Chen et al. (2008) have suggested from an ozonolysis study of methyl vinyl ketone and methacrolein that pathways leading to hydrogen peroxide via hydroxy-hydroperoxides (see Fig. 1) might be important. The decomposition of the hydroperoxides may also lead to acids. Therefore, humidity might have a significant effect on the yield of hygroscopic products, the target of the present study.

$\mathrm{OA}$ and AR have been chosen as laboratory model compounds as the product particles from both OA and AR oxidation are expected to generally represent the organic fraction of aged particles from emissions rich in fatty acids from sources listed above. For the purpose of these laboratory studies, the precursor particles are of sufficiently low volatility, and the product particles (for AR) are expected to contain a sufficient density of hygroscopic products.

\section{Experimental}

The aerosol particles were generated by passing a flow of nitrogen $\left(11 \mathrm{~min}^{-1}\right)$ over a reservoir containing OA or AR in an oven kept at $130^{\circ} \mathrm{C} \pm 2^{\circ} \mathrm{C}$ or $160^{\circ} \mathrm{C} \pm 2^{\circ} \mathrm{C}$, respectively, downstream of which OA or AR particles form by homogeneous nucleation by cooling to laboratory temperature. The particle number concentration and size distribution were continuously measured with a Scanning Mobility Particle Sizer system (SMPS). The resulting aerosol particles had a geometric mean diameter of $77 \mathrm{~nm}$ and $55 \mathrm{~nm}$ for OA and AR ( $\pm 2 \%$ for both types), respectively, with a number concentration of $5 \times 10^{6}$ particles $\mathrm{cm}^{-3}( \pm 30 \%(1 \sigma))$.

Ozone was generated by irradiating a $0.61 \mathrm{~min}^{-1}$ flow of a mixture of $40 \% \mathrm{O}_{2}$ in $\mathrm{N}_{2}$ in a quartz tube with an ultra-violet lamp (Pen-Ray 3SC-9, UV Products Ltd., USA) and diluting it to a flow of $11 \mathrm{~min}^{-1}$. The aerosol and ozone flows were mixed together directly in front of the 6.27 1 Teflon laminar flow reactor kept at room temperature and with a residence time of $6 \mathrm{~min}$. The concentration of ozone $(0.5-2 \mathrm{ppm}$ with variations $<1 \%$ during a $2 \mathrm{~h}$ time period) was measured with a photometric ozone analyzer (model ML 9810, Monitor Labs Inc, USA) downstream of the reactor in absence of aerosol. Ozone remained in excess with a depletion of at maximum $30 \%$, if aerosol was present in the reactor, consistent with reported uptake kinetics. Ozone remaining at the exit of the reactor was scrubbed from the gas using a 
potassium iodide denuder to avoid secondary chemistry in the sampling devices.

Relative humidity $(\mathrm{RH})$ in the flow reactor was adjusted separately in the two gas flows containing ozone and aerosol particles prior to mixing in front of the reactor by passing the flows through a humidifier. The latter consisted of a Goretex membrane tube partially immersed in water, the level of which could be adjusted. $\mathrm{RH}$ in the flow reactor could be adjusted from 0 to $95 \%$ at a precision of $\pm 2 \%$. It was measured using capacity sensors (Rotronic, Switzerland).

We use an hygroscopicity tandem differential mobility analyzer (H-TDMA), to characterize the particles exiting the flow reactor (Sjogren et al., 2007; Weingartner et al., 2002). Hygroscopic growth, i.e., the change in diameter due to uptake of water, of particles with diameters between 20 and $250 \mathrm{~nm}$ was determined at room temperature and in the humidity range of $10 \%$ to $95 \% \mathrm{RH}$ with an accuracy of $0.1^{\circ} \mathrm{C}$ and $1.6 \%$, respectively. In the present experiments, the aerosol particles (flow rate: $0.31 \mathrm{~min}^{-1}$ ) first entered a silica gel diffusion dryer in order to dry the sample to $<10 \%$ $\mathrm{RH}$ at $25^{\circ} \mathrm{C}$. The dry aerosol is then brought to equilibrium charge with a diffusion charger $\left({ }^{85} \mathrm{Kr}\right)$ and fed into the first differential mobility analyser (DMA), where a narrow size range of dry aerosol ( $100 \mathrm{~nm}$ for OA and $68.5 \mathrm{~nm}$ for AR) is chosen. The monodispersed aerosol is then conditioned to a well-defined higher RH during $1 \mathrm{~min}$. We have tested that $1 \mathrm{~min}$. is sufficient to establish equilibrium between aerosol and water vapour. The aerosol particle diameter $(D)$ is then measured using the second DMA and a condensation particle counter (CPC, 3022A, TSI, USA). The GF is defined as the ratio of the humidified particle diameter $(D)$ to the dry particle diameter $\left(D_{0}\right)$. A humidogram describes the GF as a function of RH. Some substances show a hysteresis behaviour (forming a meta-stable supersaturated solution). Therefore, in addition to the procedure described above, during which the aerosol is exposed to a certain $\mathrm{RH}$ from an initially dry condition, denoted as hydration case, the monodisperse aerosol is also exposed first to $\mathrm{RH}>80 \%$, and then to the final RH, which is denoted as the dehydration case.

We use proton nuclear magnetic resonance spectroscopy $\left({ }^{1} \mathrm{H}-\mathrm{NMR}\right)$, which is a suitable method to characterize complex mixtures of organic compounds, also with variable water content, in terms of its functional group composition (Decesari et al., 2000; Samburova et al., 2007). Filter samples were collected at the exit of the flow reactor during $2 \mathrm{~h}$ on a Teflon coated quartz fiber filter (TQFF) (PALLFLEX Membrane Filters, PALL Gelman, USA). ${ }^{1} \mathrm{H}-\mathrm{NMR}$ spectra were obtained at a frequency of $600 \mathrm{MHz}$ on a model LA400 spectrometer from JEOL (Tokyo, Japan) with a model FG-400 probe from Nanorac Cryogenics Corp. (Tokyo, Japan). Chemical shifts are reported in ppm. The filters were extracted with fully deuterated methyl sulfoxide- $\mathrm{d}_{6}$ (DMSO-d 6 ) (99.9 atom \% D, Aldrich), which allows observing the proton signals of the main functional groups directly in the spectra (Samburova et al., 2007). Dibromomethane $\left(\mathrm{CH}_{2} \mathrm{Br}_{2}\right)$ was added as internal quantification standard, as it gives a well resolved peak in the region of vinyl protons at $5.5 \mathrm{ppm}$. A detailed description of this procedure is given by Samburova et al. (2007). Carboxylic acid protons appeared as a group of peaks (10.5-14 ppm), well separated from aliphatic protons $(0.5-2 \mathrm{ppm})$, which are in $\beta$-position and further away from an acid or carbonyl group. The unavoidable signals from DMSO- $\mathrm{d}_{6}$ and trace amounts of water at 2.50 and $3.31 \mathrm{ppm}$, respectively, partially overlap with signals from aliphatic protons $\left(-\mathrm{CH}_{n}\right)$ in $\alpha$-position to a carboxylic (COOH) or carbonyl group. Only those in $\beta$-position or further away from oxygenated groups were included to calculate ratios of carboxylic to aliphatic protons.

\section{Results and discussion}

Figure 2a shows typical humidograms of processed and unprocessed OA aerosol. They show that the unprocessed OA particles take up only insignificant amounts of water, with the GF of OA being 1.01 at $93 \%$ RH. This would correspond to about 2.5 formal monolayers of water on the surface or to about $1 \%$ volume fraction, consistent with the very low solubility of $\mathrm{OA}$ due to its long hydrophobic $\mathrm{C}_{18}$ chain. Similar results were observed on OA films, drops and levitated particles (Asad et al., 2004; Hung et al., 2005; Lee and Chan, 2007a). A humidogram of OA aerosol processed by $1.84 \mathrm{ppm}$ ozone (corresponding to an exposure of $6.7 \times 10^{-4} \mathrm{~atm} \mathrm{~s}$ ) and at $75 \% \mathrm{RH}$ in the reactor is also shown in Fig. 2a. The measured GF of the processed OA aerosol slightly increased to 1.03 at $93 \% \mathrm{RH}$ as compared to unprocessed OA aerosol. We did not observe any indication of deliquescence, nor did we observe any difference between humidograms obtained in hydration and dehydration mode (data lumped in Fig. 2). We did also not observe a significant change to this GF, when we performed the experiment at lower ozone concentration down to $0.5 \mathrm{ppm}$ and lower humidity. The diameter growth factors reported here for processed and unprocessed OA particles are fully consistent with the mass growth factors observed by Lee and Chan (2007a) for levitated particles about 50 micrometer in diameter of about $1 \%$ and $3 \%$, respectively, at $90 \% \mathrm{RH}$. The latter experiments were performed at ozone concentrations a factor of 2 to 8 lower than ours, but over much longer periods of time (up to $20 \mathrm{~h}$ ).

As shown previously, the reaction of ozone with OA produces a variety of oxygenated products such as azelaic acid, nonanoic acid, 9-oxo-nonanoic acid and nonanal (Hung et al., 2005; Katrib et al., 2004; Moise and Rudich, 2002; Smith et al., 2002; Thornberry and Abbatt, 2004; Zahardis et al., 2005; Ziemann, 2005), some polymeric products (Hearn and Smith, 2005; Hung et al., 2005; Zahardis et al., 2005; Ziemann, 2005; Reynolds et al., 2006) and high-molecularweight organic compounds (Hung et al., 2005; Zahardis et 


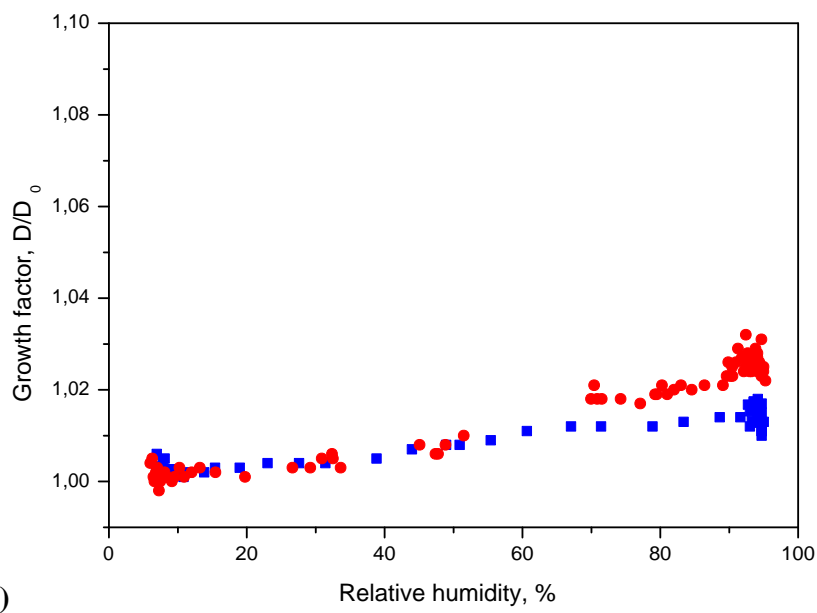

(a)

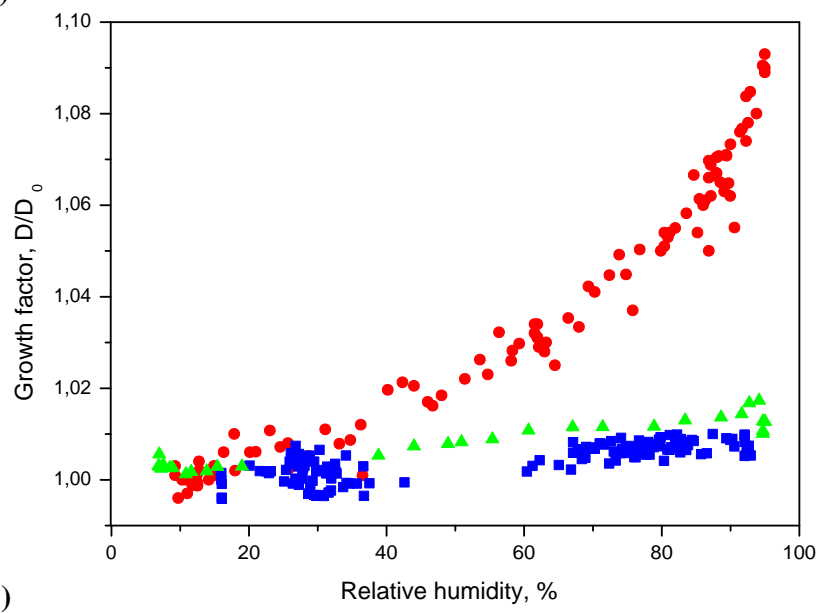

(b)

Fig. 2. Humidograms of oxidized OA (a) and AR (b) particles as function of RH in the H-TDMA. Red circles and blue squares denote the GF of particles processed with $1.85 \mathrm{ppm}$ ozone at $75 \% \mathrm{RH}$ in the reactor and of unprocessed particles, respectively. The green triangles denote the GF of AR particles processed with $1.80 \mathrm{ppm}$ ozone under dry conditions.

al., 2005; Ziemann, 2005). Even though some of the smaller products contain carboxylic acid groups that lead to a slightly increased water uptake, they are insoluble in water and not hygroscopic, as shown previously for pure azelaic acid (Andrews and Larson, 1993). In addition, the recent aerosol studies by Hearn and Smith (2005) and Katrib et al. (2005) suggest that these species are only minor reaction products.

In contrast, at ozone exposures orders of magnitude higher than in our study, Asad et al. (2004) (0.81 atm s) and Hung et al. (2005) (0.16 atm s) observed a significant increase of adsorbed water mass on an OA film and hygroscopic volume growth of deposited OA drops, respectively. Comparable to the hygroscopic behavior, Broekhuizen et al. (2004) measured an increased $\mathrm{CCN}$ activity at a supersaturation of $0.6 \%$ after ozone exposures higher than $0.14 \mathrm{~atm} \mathrm{~s}$. These effects were probably due to further destruction of primary reaction products into smaller, more soluble organic species (Nepotchatykh and Ariya, 2002). Therefore, the previous experiments were only able to demonstrate increased water uptake after oxidation at ozone concentrations high enough to allow secondary chemistry leading to soluble products that will not be operative under atmospheric conditions (Zahardis and Petrucci, 2007). Our present data, consistent with those by Lee and Chan (2007a), obtained at ozone concentrations of 0.5 to 2 ppm demonstrate that OA ozonolysis under atmospheric conditions is not leading to hygroscopic products.

As in the case of OA, the humidogram of unprocessed AR aerosol shows only very little size changes with relative humidity (Fig. 2b). When AR aerosol was processed with ozone under dry conditions and an ozone concentration of 0.5 or $2.0 \mathrm{ppm}$, corresponding to exposures of $1.8 \times 10^{-4}$ atm $\mathrm{s}$ and $6.7 \times 10^{-4} \mathrm{~atm} \mathrm{~s}$, respectively, no increase in hygroscopic growth was observed, similar to the OA case. However, when the humidity in the reactor was set to $75 \%$, a significantly increased hygroscopic growth was observed, e.g. at 1.84 ppm ozone, as shown in Fig. 2b. Here, the processed AR aerosol shows a monotonically increasing humidogram, and the observed GF at 95\% RH in the H-TDMA is 1.09. Again, no indications of deliquescence were evident and hydration and dehydration curves were identical.

In contrast to the case of OA, ozonolysis of $\mathrm{AR}$ is expected to result in short C3-C6 multifunctional organic compounds as first generation products that contain carboxylic and carbonyl groups, some of which are soluble and hygroscopic. For example, pure malonic (MA) and glutaric acid (GA), which would result from cleavage at all double bonds and decomposition of the corresponding CIs via pathway (1) in Fig. 1, have GFs 1.73 and 1.29 at 90\% RH (Prenni et al., 2003), respectively. From this perspective it is surprising that under dry conditions, the hygroscopic growth factors would not respond more significantly to ozonolysis. Also in a recent study by Lee and Chan (2007b) on ozonolysis of linoleic and linolenic acids under dry conditions, the mass growth factors hardly increased compared to oleic acid ozonolysis mentioned above. One aspect may certainly be the fact that the most hygroscopic products expected from AR ozonolysis, MA and GA, may undergo significant evaporation $(\mathrm{Ku}-$ mar et al., 2003; Koehler et al., 2006; Rissmann et al., 2007). However, we do not believe that they would be entirely depleted from the particles at the time of the HTDMA measurement. Therefore the differences in growth factors observed between dry and humid ozonolysis indicate that either water significantly accelerated the kinetics or changed the chemical mechanism. A more physical aspect might be that at high humidity, the formation of soluble products leads to a swelling of the particles due to water uptake and thus facilitates the access of ozone into the bulk of the particles for further processing.

At high humidity (75\%), the GF gradually increased with increasing ozone concentration (Fig. 3a), indicating that no second order effects are playing a substantial role. Similarly, 


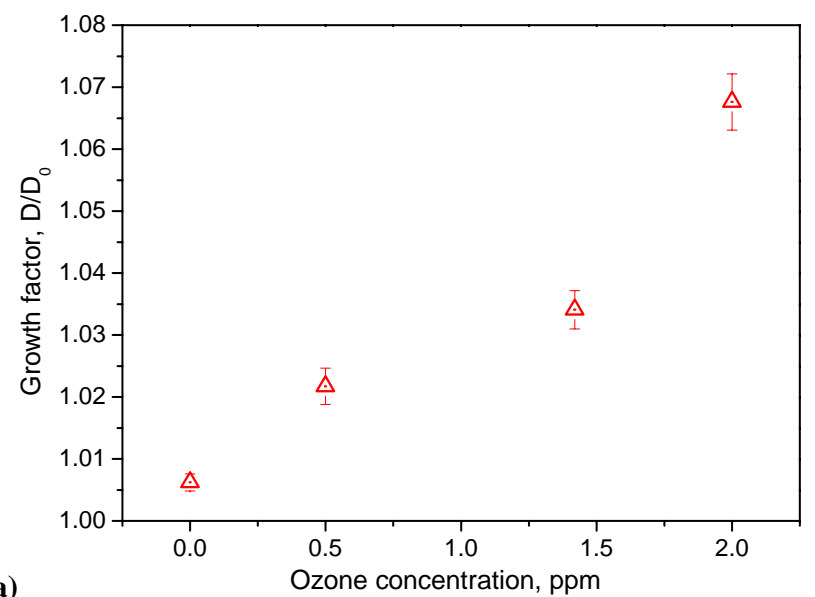

(a)

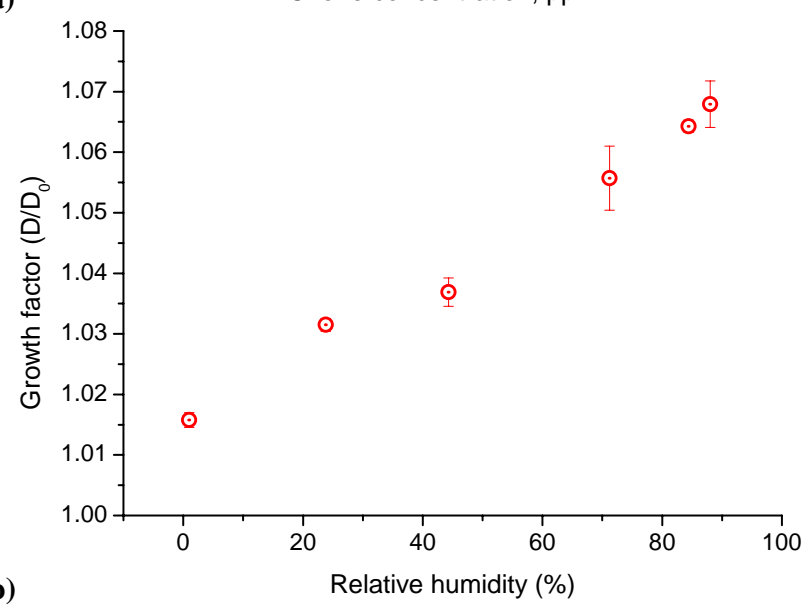

Fig. 3. (a) Hygroscopic growth factor of the oxidized AR particles as a function of the ozone concentration. The humidity in the aerosol flow reactor was $75 \%$ RH. (b) Hygroscopic growth factor of AR particles processed with $1.84 \mathrm{ppm}$ ozone as a function of the relative humidity in the aerosol flow reactor. H-TDMA measurements were extrapolated to $90 \% \mathrm{RH}$. The error bars represent the standard deviations.

the GF increased gradually with increasing humidity during ozonolysis at constant ozone exposure of $6.7 \times 10^{-4} \mathrm{~atm} \mathrm{~s}$ (Fig. 3b).

Using ${ }^{1} \mathrm{H}-\mathrm{NMR}$, the ratio of acid protons to aliphatic protons in $\beta$-position and further away from the acid groups was determined for samples taken during experiments peformed under dry conditions, at $27 \%, 46 \%, 72 \%$ and $82 \%$ RH. They show a parallel increase with RH to that of the GF. Figure 4 displays the correlation between the measured GF and the ratio of acid to aliphatic protons. Due to the limited access to the NMR instrument, we could only take a few samples from one experimental run at a given humidity, so that the error bars do not account for the day to day variability. As mentioned in the experimental section, due to spectral overlap, only protons in $\beta$-position and further away from the acid group are included in the ratio displayed here. For the

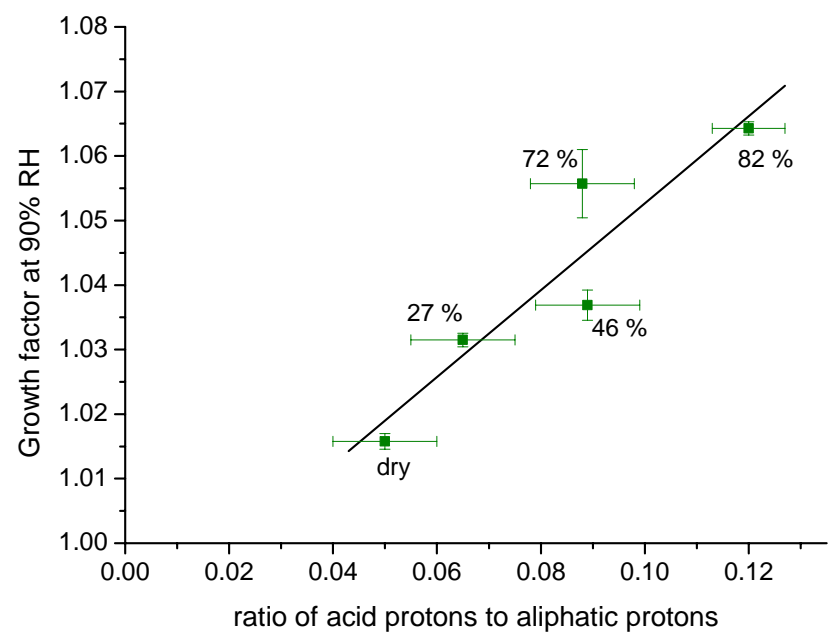

Fig. 4. Correlation of the hygroscopic growth factor at $90 \% \mathrm{RH}$ in the H-TDMA with the ratio of the concentration of acid protons to that of aliphatic protons determined by ${ }^{1} \mathrm{H}-\mathrm{NMR}$. Each data point corresponds to experiments performed at the relative humidity indicated and at $1.84 \mathrm{ppm}$ ozone in the flow reactor. Error bars are standard deviations of samples obtained during the same experimental run.

reactant $\mathrm{AR}$, this ratio is 0.034 , due to $1 \mathrm{COOH}$ proton and 29 aliphatic protons in $\beta$-position and further away. Under dry ozonolysis conditions, this ratio reached 0.055 indicating a small but already significant increase of the density of acid groups. For ozonolysis at $82 \% \mathrm{RH}$, the ratio of acid to aliphatic protons increased to 0.12 , i.e., by a factor of 3.5 as compared to the parent AR, or a factor of about 2 compared to ozonolysis under dry conditions. Two caveats are appropriate with respect to this analysis. The evaporation of the smaller dicarboxylic acids that strongly contribute to a high $\mathrm{COOH}-\mathrm{H}$ to $\mathrm{CH}_{n}-\mathrm{H}$ ratio may be more substantial on the filter while sampling than during the short residence time in HTDMA experiment. The other aspect is the fact that the HTDMA experiments were performed with fixed particle sizes, roughly at the mode of the aerosol number size distribution, while the mass of material sampled for the ${ }^{1} \mathrm{H}$-NMR analysis is dominated by the larger particles that may have been processed to a lesser degree than the smaller ones. In both cases, the measured GF may have referred to not exactly the same composition as the $\mathrm{COOH}-\mathrm{H}$ to $\mathrm{CH}_{n}-\mathrm{H}$ ratio.

In an attempt to rationalize the growth factor measured under humid conditions, we could consider the extreme case that the product particles consist of a mixture of MA and AR only. Each MA molecule contributes two acid protons, but no aliphatic proton in $\beta$-position, while each AR molecule contributes one acidic proton and 29 aliphatic protons. The observed $\mathrm{COOH}-\mathrm{H}$ to $\mathrm{CH}_{n}-\mathrm{H}$ ratio of 0.12 would then correspond to a mixture of $45 \% \mathrm{AR}$ and $55 \% \mathrm{MA}$. Using the Zdanovskii, Stokes, and Robinson (ZSR) method (Cruz and Pandis, 2000), assuming ideal behaviour of solutes present 
and taking a growth factor of 1.01 for AR and 1.73 for MA, we get a GF of 1.41 for the mixture, much larger than what was measured. If we do the same analysis assuming GA acid as the only other species in the mix contributing 2 acidic and 2 aliphatic protons, the measured proton ratio of 0.12 would correspond to $58 \% \mathrm{GA}$ and $42 \% \mathrm{AR}$, giving a growth factor of 1.17, still higher than what was measured. Longer chain diacids, monoacids or oxoacids are less soluble. They contribute to the acidic protons measured by NMR but not significantly to the hygroscopic GF and may explain the offset in the correlation plot. Therefore, this analysis indicates that the increased $\mathrm{COOH}-\mathrm{H}$ to $\mathrm{CH}_{n}-\mathrm{H}$ ratio from ozonolysis under humid conditions is likely caused by an increased presence of the small dicarboxylic acids. This suggests that the chemical mechanism under humid conditions promotes the formation of acids more than under dry conditions.

According to the "dry mechanism" of condensed phase alkene ozonolysis (see Fig. 1), the ozonolysis starts with the addition of ozone into the double bond and the formation of the primary ozonide, which is unstable and decomposes into an aldehyde and the Criegee Intermediate (CI). This CI could (Zahardis and Petrucci, 2007): (1) isomerize and form an acid group (eventually leading among others to MA and GA for AR ozonolysis, as mentioned above), (2) react with an aldehyde and form a secondary ozonide, (3) react with an acid group and form a hydroperoxide, (4) react with another CI and form a diperoxide. Depending on the matrix, these reactions can continue and lead to high-molecular weight compounds or further to oligomers. In addition to these processes, for polyunsaturated fatty acids, autoxidation processes could also contribute, especially at low ozone concentrations and over long time scales (Lee and Chan, 2007b).

The presence of water vapor during ozonolysis could influence the mechanism described above in several ways, e.g., by inhibiting or promoting isomerization or the reaction with an acid. Most likely, in analogy to the corresponding gas phase chemistry, water can react with a CI and form a hydroxyhydroperoxide (HHP, pathway (5)), that in turn decomposes heterogeneously to form either a carbonyl and $\mathrm{H}_{2} \mathrm{O}_{2}$ or a carboxylic acid and $\mathrm{H}_{2} \mathrm{O}$ (Hasson et al., 2001a; Horie et al., 1994). Therefore, this pathway (5) competes with (3), the reaction of $\mathrm{CI}$ with an acid. As our results show, the reaction with water seems to promote the formation of small water soluble acids, possibly at the expense of larger molecular weight complexes formed under dry conditions. We also note that even if in (5) only a small fraction decomposes into the acid and the majority into the aldehyde, the short aldehydes formed in AR ozonolysis are volatile and mostly lost to the gas phase, while the acids are more likely to remain in the aerosol phase in spite of the evaporation losses mentioned above also for them. This additionally increases the overall content of acids in the aerosol phase and especially the small dicarboxylic acid fraction, which are the most hygroscopic.

\section{Conclusions and atmospheric implications}

This study shows that a polyunsaturated fatty acid, such as $\mathrm{AR}$, is a good model system to follow hygroscopic changes induced by oxidation of organic aerosol particles with an atmospherically relevant ozone exposure, and that water plays an important role in condensed phase alkene oxidation. Similar effects could not be demonstrated with a widely used proxy for such studies, OA, under these conditions. The ozone exposures used in the present experiments, namely from 0.5 to $2 \mathrm{ppm}$ during the experimental reaction time (6 min) correspond to about $20 \mathrm{~h}$ exposure in the remote atmosphere. The effects were linearly varying with ozone concentration in this range, indicating that second-order effects were not playing a role.

In this laboratory study, we worked with simple model compounds in their pure form. Even though these particle do not directly compare to real atmospheric particles in structure and composition, we recall that in many environments, the mass fraction of fatty acids can be substantial and among these, the fraction of unsaturated representatives may even exceed the saturated ones, as mentioned in the introduction section.

Under dry conditions, ozonolysis of condensed phase alkenes, either pure or in mixtures with a protic matrix such as acids, is characterized by the formation of nonhygroscopic high molecular weight products. Under humid conditions, the reaction of water with the CIs might open a pathway for the formation of smaller acids that lead to more significant changes in hygroscopicity and possibly also in CCN activity.

In spite of the nice correlation between the functional group analysis and the hygroscopic growth factors, this relation remains somewhat qualitative in character, as without more detailed product information a direct quantitative prediction of the growth factor is not possible. Nevertheless, the effect of water to provide a competing pathway during ozonolysis observed in this study is a reminder that the properties of a complex aerosol are not a simple superposition of the properties of its individual components.

Acknowledgements. The authors gratefully acknowledge T. Didenko (Laboratory of Physical Chemistry, ETH Zurich) for carrying out ${ }^{1} \mathrm{H}-\mathrm{NMR}$ measurements. This work was supported by the National Science Foundation Switzerland (grant $n^{\circ} 200021$ 100280).

Edited by: C. George 


\section{References}

Andrews, E. and Larson, S. M.: Effect of surfactant layers on the size changes of aerosol-particles as a function of relativehumidity, Environ. Sci. Technol., 27, 857-865, 1993.

Asad, A., Mmereki, B. T., and Donaldson, D. J.: Enhanced uptake of water by oxidatively processed oleic acid, Atmos. Chem. Phys., 4, 2083-2089, 2004, http://www.atmos-chem-phys.net/4/2083/2004/.

Chen, Z. M., Wang, H. L., Zhu, L. H., Wang, C. X., Jie, C. Y., and Hua, W.: Aqueous-phase ozonolysis of methacrolein and methyl vinyl ketone: a potentially important source of atmospheric aqueous oxidants, Atmos. Chem. Phys., 8, 2255-2265, 2008, http://www.atmos-chem-phys.net/8/2255/2008/.

Cheng, Y., Li, S. M., Leithead, A., Brickell, P. C., and Leaitch, W. R.: Characterizations of cis-pinonic acid and $n$-fatty acids on fine aerosols in the lower fraser valley during pacific 2001 air quality study, Atmos. Environ., 38, 5789-5800, 2004.

Cruz, C. N. and Pandis, S. N.: Deliquescence and hygroscopic growth of mixed inorganic-organic atmospheric aerosol, Environ. Sci. Technol., 34, 4313-4319, 2000.

Decesari, S., Facchini, M. C., Fuzzi, S., and Tagliavini, E.: Characterization of water-soluble organic compounds in atmospheric aerosol: A new approach, J. Geophys. Res.-Atmos., 105, 14811489, 2000.

Ellison, G. B., Tuck, A. F., and Vaida, V.: Atmospheric processing of organic aerosols, J. Geophys. Res.-Atmos., 104, 11633 $11641,1999$.

Hasson, A. S., Orzechowska, G., and Paulson, S. E.: Production of stabilized criegee intermediates and peroxides in the gas phase ozonolysis of alkenes 1 . Ethene, trans-2-butene, and 2,3-dimethyl-2-butene, J. Geophys. Res.-Atmos., 106, 34 13134 142, 2001a.

Hearn, J. D., and Smith, G. D.: Measuring rates of reaction in supercooled organic particles with implications for atmospheric aerosol, Phys. Chem. Chem. Phys., 7, 2549-2551, 2005.

Horie, O., Neeb, P., Limbach, S., and Moortgat, G. K.: Formation of formic-acid and organic peroxides in the ozonolysis of ethene with added water-vapor, Geophys. Res. Lett., 21, 15231526, 1994.

Hung, H. M., Katrib, Y., and Martin, S. T.: Products and mechanisms of the reaction of oleic acid with ozone and nitrate radical, J. Phys. Chem. A, 109, 4517-4530, 2005.

Hung, H. M. and Ariya, P.: Oxidation of oleic acid and oleic acid/sodium chloride(aq) mixture droplets with ozone: Changes of hygroscopicity and role of secondary reactions, J. Phys. Chem. A, 111, 620-632, 2007.

Jacobson, M. C., Hansson, H. C., Noone, K. J., and Charlson, R. J.: Organic atmospheric aerosols: Review and state of the science, Rev. Geophys., 38, 267-294, 2000.

Kanakidou, M., Seinfeld, J. H., Pandis, S. N., Barnes, I., Dentener, F. J., Facchini, M. C., Van Dingenen, R., Ervens, B., Nenes, A., Nielsen, C. J., Swietlicki, E., Putaud, J. P., Balkanski, Y., Fuzzi, S., Horth, J., Moortgat, G. K., Winterhalter, R., Myhre, C. E. L., Tsigaridis, K., Vignati, E., Stephanou, E. G., and Wilson, J.: Organic aerosol and global climate modelling: A review, Atmos. Chem. Phys., 5, 1053-1123, 2005,

http://www.atmos-chem-phys.net/5/1053/2005/.
Katrib, Y., Martin, S. T., Hung, H. M., Rudich, Y., Zhang, H. Z., Slowik, J. G., Davidovits, P., Jayne, J. T., and Worsnop, D. R.: Products and mechanisms of ozone reactions with oleic acid for aerosol particles having core-shell morphologies, J. Phys. Chem. A, 108, 6686-6695, 2004.

Kawamura, K. and Gagosian, R. B.: Implications of omegaoxocarboxylic acids in the remote marine atmosphere for photooxidation of unsaturated fatty-acids, Nature, 325, 330-332, 1987.

Koehler, K. A., Kreidenweis, S. M., DeMott, P. J., Prenni, A. J., Carrico, C. M., Ervens, B., and Feingold, G.: Water activity and activation diameters from hygroscopicity data - Part II: Application to organic species, Atmos. Chem. Phys., 6, 795-809, 2006, http://www.atmos-chem-phys.net/6/795/2006/.

Kumar, P. P., Broekhuizen, K., and Abbatt, J. P. D.: Organic acids as cloud condensation nuclei: Laboratory studies of highly soluble and insoluble species, Atmos. Chem. Phys., 3, 509-520, 2003, http://www.atmos-chem-phys.net/3/509/2003/.

Lee, A. K. Y. and Chan, C. K.: Single particle Raman spectroscopy for investigating atmospheric heterogeneous reactions of organic aerosols, Atmos. Environ., 41, 4611-4621, 2007a.

Lee, A. K. Y. and Chan, C. K.: Heterogeneous reactions of linoleic acid and linolenic acid particles with ozone: Reaction pathways and changes in particle mass, hygroscopicity, and morphology, J. Phys. Chem. A, 111, 6285-6295, 2007b.

Makar, P. A.: The estimation of organic gas vapour pressure, Atmos. Environ., 35, 961-974, 2001.

Mochida, M., Kitamori, Y., Kawamura, K., Nojiri, Y., and Suzuki, K.: Fatty acids in the marine atmosphere: Factors governing their concentrations and evaluation of organic films on sea-salt particles, J. Geophys. Res.-Atmos., 107, 4325, doi:10.1029/2001JD001278, 2002.

Moise, T. and Rudich, Y.: Reactive uptake of ozone by aerosolassociated unsaturated fatty acids: Kinetics, mechanism, and products, J. Phys. Chem. A, 106, 6469-6476, 2002.

Nepotchatykh, O. V. and Ariya, P. A.: Degradation of dicarboxylic acids (C2-C9) upon liquid-phase reactions with $\mathrm{O}_{3}$ and its atmospheric implications, Environ. Sci. Technol., 36, 3265-3269, 2002.

Novakov, T. and Penner, J. E.: Large contribution of organic aerosols to cloud-condensation-nuclei concentrations, Nature, 365, 823-826, 1993.

Oros, D. R. and Simoneit, B. R. T.: Identification and emission rates of molecular tracers in coal smoke particulate matter, Fuel, 79, 515-536, 2000.

Oros, D. R. and Simoneit, B. R. T.: Identification and emission factors of molecular tracers in organic aerosols from biomass burning part 1. Temperate climate conifers, Appl. Geochem., 16, 1513-1544, 2001.

Polzer, J. and Bachmann, K.: Determination of fatty-acids in atmospheric samples via gc/ms, Fresen. J. Anal. Chem., 340, 555559, 1991.

Prenni, A. J., De Mott, P. J., and Kreidenweis, S. M.: Water uptake of internally mixed particles containing ammonium sulfate and dicarboxylic acids, Atmos. Environ., 37, 4243-4251, 2003. 
Reynolds, J. C., Last, D. J., McGillen, M., Nijs, A., Horn, A. B., Percival, C., Carpenter, L. J., and Lewis, A. C.: Structural analysis of oligomeric molecules formed from the reaction products of oleic acid ozonolysis, Environ. Sci. Technol., 40, 6674-6681, 2006.

Rissman, T. A., Varutbangkul, V., Surratt, J. D., Topping, D. O., McFiggans, G., Flagan, R. C., and Seinfeld, J. H.: Cloud condensation nucleus $(\mathrm{CCN})$ behavior of organic aerosol particles generated by atomization of water and methanol solutions, Atmos. Chem. Phys., 7, 2949-2971, 2007, http://www.atmos-chem-phys.net/7/2949/2007/.

Rogge, W. F., Hildemann, L. M., Mazurek, M. A., Cass, G. R., and Simonelt, B. R. T.: Sources of fine organic aerosol.1. Charbroilers and meat cooking operations, Environ. Sci. Technol., 25, 1112-1125, 1991.

Rogge, W. F., Mazurek, M. A., Hildemann, L. M., Cass, G. R., and Simoneit, B. R. T.: Quantification of urban organic aerosols at a molecular-level - identification, abundance and seasonalvariation, Atmos. Environ. A-Gen., 27, 1309-1330, 1993.

Samburova, V., Didenko, T., Kunenkov, E., Emmenegger, C., Zenobi, R., and Kalberer, M.: Functional group analysis of high molecular weight compounds in the water-soluble fraction of organic aerosols, Atmos. Environ., 41, 4703-4710, 2007.

Schauer, J. J., Kleeman, M. J., Cass, G. R., and Simoneit, B. R. T.: Measurement of emissions from air pollution sources. 1. C-1 through c-29 organic compounds from meat charbroiling, Environ. Sci. Technol., 33, 1566-1577, 1999.

Seinfeld, J. H. and Pandis, S. N.: Athmospheric chemistry and physics: From air polution to climate change, John Wiley \& Sons, Inc., New York, USA, 1998.

Simoneit, B. R. T., and Mazurek, M. A.: Organic-matter of the troposphere.2. Natural background of biogenic lipid matter in aerosols over the rural western united-states, Atmos. Environ., 16, 2139-2159, 1982.

Simoneit, B. R. T., Cox, R. E., and Standley, L. J.: Organic-matter of the troposphere.4. Lipids in harmattan aerosols of nigeria, Atmos. Environ., 22, 983-1004, 1988.
Sjogren, S., Gysel, M., Weingartner, E., Baltensperger, U., Cubison, M. J., Coe, H., Zardini, A. A., Marcolli, C., Krieger, U. K., and Peter, T.: Hygroscopic growth and water uptake kinetics of twophase aerosol particles consisting of ammonium sulfate, adipic and humic acid mixtures, J. Aerosol Sci., 38, 157-171, 2007.

Smith, G. D., Woods, E., DeForest, C. L., Baer, T., and Miller, R. E.: Reactive uptake of ozone by oleic acid aerosol particles: Application of single-particle mass spectrometry to heterogeneous reaction kinetics, J. Phys. Chem. A, 106, 8085-8095, 2002.

Tervahattu, H., Hartonen, K., Kerminen, V. M., Kupiainen, K., Aarnio, P., Koskentalo, T., Tuck, A. F., and Vaida, V.: New evidence of an organic layer on marine aerosols, J. Geophys. Res.Atmos., 107, 4053, doi:10.1029/2000JD000282, 2002.

Thornberry, T. and Abbatt, J. P. D.: Heterogeneous reaction of ozone with liquid unsaturated fatty acids: Detailed kinetics and gas-phase product studies, Phys. Chem. Chem. Phys., 6, 84-93, 2004.

Wang, G. H., Kawamura, K., Watanabe, T., Lee, S. C., Ho, K. F., and Cao, J. J.: High loadings and source strengths of organic aerosols in china, Geophys. Res. Lett., 33, L22801, doi:10.1029/2006GL027624, 2006.

Weingartner, E., Gysel, M., and Baltensperger, U.: Hygroscopicity of aerosol particles at low temperatures. 1. New low-temperature h-tdma instrument: Setup and first applications, Environ. Sci. Technol., 36, 55-62, 2002.

Zahardis, J., LaFranchi, B. W., and Petrucci, G. A.: Photoelectron resonance capture ionization-aerosol mass spectrometry of the ozonolysis products of oleic acid particles: Direct measure of higher molecular weight oxygenates, J. Geophys. Res.-Atmos., 110, D08307, doi:10.1029/2004JD005336, 2005.

Zahardis, J. and Petrucci, G. A.: The oleic acid-ozone heterogeneous reaction system: Products, kinetics, secondary chemistry, and atmospheric implications of a model system - a review, Atmos. Chem. Phys., 7, 1237-1274, 2007, http://www.atmos-chem-phys.net/7/1237/2007/.

Ziemann, P. J.: Aerosol products, mechanisms, and kinetics of heterogeneous reactions of ozone with oleic acid in pure and mixed particles, Faraday Discuss., 130, 469-490, 2005 